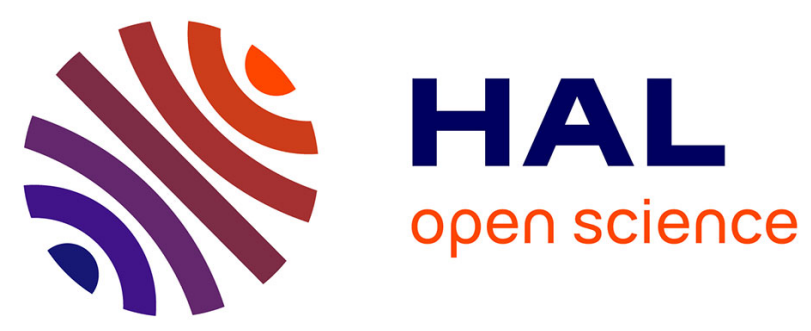

\title{
Evidence for the Trophic Transfer of Perfluoroalkylated Substances in a Temperate Macrotidal Estuary
}

Gabriel Munoz, Hélène Budzinski, Marc Babut, Hilaire Drouineau, Mathilde

Lauzent, Karyn Le Menach, Jérémy Lobry, Jonathan Selleslagh, Caroline

Simonnet-Laprade, Pierre Labadie

\section{To cite this version:}

Gabriel Munoz, Hélène Budzinski, Marc Babut, Hilaire Drouineau, Mathilde Lauzent, et al.. Evidence for the Trophic Transfer of Perfluoroalkylated Substances in a Temperate Macrotidal Estuary. Environmental Science and Technology, 2017, 51 (15), pp.8450-8459. 10.1021/acs.est.7b02399 . hal02067250

\section{HAL Id: hal-02067250 \\ https://hal.science/hal-02067250}

Submitted on 14 Mar 2019

HAL is a multi-disciplinary open access archive for the deposit and dissemination of scientific research documents, whether they are published or not. The documents may come from teaching and research institutions in France or abroad, or from public or private research centers.
L'archive ouverte pluridisciplinaire HAL, est destinée au dépôt et à la diffusion de documents scientifiques de niveau recherche, publiés ou non, émanant des établissements d'enseignement et de recherche français ou étrangers, des laboratoires publics ou privés. 
Evidence for the Trophic Transfer of Perfluoroalkylated Substances in a Temperate Macrotidal Estuary

Gabriel Munoz ${ }^{1}$, Hélène Budzinski ${ }^{2}$, Marc Babut ${ }^{3}$, Hilaire Drouineau ${ }^{4}$, Mathilde Lauzent ${ }^{1}$, Karyn Le Menach², Jérémy Lobry ${ }^{4}$, Jonathan Selleslagh ${ }^{4}$, Caroline Simonnet-Laprade ${ }^{1}$, Pierre Labadie ${ }^{2^{*}}$

1: Université de Bordeaux, EPOC, UMR 5805, LPTC Research Group, F-33400 Talence, France.

2: CNRS, EPOC, UMR 5805, LPTC Research Group F-33400 Talence, France

3: IRSTEA, UR MALY, F-69616 Villeurbanne cedex, France.

4: IRSTEA, UR EABX, F-33610 Cestas, France.

${ }^{*}$ Corresponding author. Contact: pierre.labadie@u-bordeaux.fr

Environ. Sci. Technol. 2017, 51, 15, 8450-8459

DOI: 10.1021/acs.est.7b02399 
Graphical Abstract

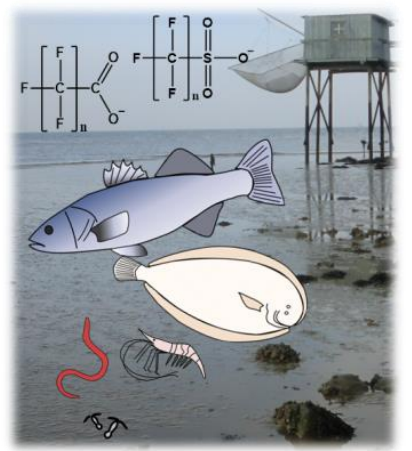




\begin{abstract}
The present survey examines the trophodynamics of a suite of 19 perfluoroalkyl substances (PFASs) in a temperate macrotidal estuary (Gironde, SW France). Across the 147 biota samples (18 taxa) collected, perfluorooctane sulfonate (PFOS), perfluorooctane sulfonamide (FOSA) and $\mathrm{C}_{8}-\mathrm{C}_{14}$ perfluoroalkyl carboxylates (PFCAs) were the most recurrent analytes. $\Sigma$ PFASs ranged between $0.66-$ $45 \mathrm{ng} \mathrm{g}^{-1}$ wet weight whole-body. Benthic organisms had relatively high $\Sigma$ PFASs compared to demersal organisms and displayed specific composition profiles with higher relative abundances of $\mathrm{C}_{8}$ and $\mathrm{C}_{9}$ PFCAs. Trophic magnification factors (TMFs) were determined through the use of linear mixed effect models including censored data, thereby considering data below detection limits as well as the interspecific variability of $\delta^{15} \mathrm{~N}$ and PFAS levels (random effects). TMFs were almost consistently $>1$ in the benthic food web as well as when considering all data pooled together, providing evidence for the biomagnification of several PFASs in estuarine environments. In addition, in contrast with previous observations, TMFs determined in the estuarine benthic web were found to significantly decrease with increasing chain length for $\mathrm{C}_{8}-\mathrm{C}_{14} \mathrm{PFCAs}$ and $\mathrm{C}_{6}-\mathrm{C}_{8}$ perfluoroalkyl sulfonates. This suggests that PFAS chemical structure might not be necessarily predictive of TMFs, which are also influenced by the trophic web characteristics.
\end{abstract}




\section{Introduction}

Halogenated organic compounds encompass a broad range of molecules that have the potential to be persistent, bioaccumulative and toxic, the present cornerstones of chemical hazard evaluation. ${ }^{1}$ Organochlorine pesticides and polychlorinated biphenyls fulfill such criteria and have been the focus of intense regulatory action and monitoring since the 1970s. ${ }^{2}$ Perfluoroalkyl and polyfluoroalkyl substances (PFASs), in contrast, came under scrutiny more recently (late 1990s) when the occurrence of perfluoroalkyl acids (PFAAs) -notably, perfluoroalkyl carboxylates (PFCAs) and perfluoroalkyl sulfonates (PFSAs)- across multiple environmental media was revealed. ${ }^{3,4}$ Since then, academic research on PFOS and related compounds has been extensive, and PFASs have been recognized as ubiquitous pollutants with potential for long range transport. ${ }^{5,6}$ The long-chained PFAAs (i.e. PFCAs bearing 8 or more carbon atoms and PFSAs of 6 or more carbon atoms) are of particular concern due to their partitioning properties and toxicity potential. This provided the grounds for the addition of perfluorooctane sulfonate (PFOS) to Annex B of the Stockholm Convention on persistent organic pollutants (POPs) in 2009. ${ }^{7}$

In biota, PFASs are found predominantly in protein-rich compartments such as blood and liver, rather than in lipid-rich tissues, a somewhat unique feature amongst POPs. ${ }^{8-10}$ In view of these specific characteristics, the bioaccumulation potential of anionic PFASs such as PFSAs and PFCAs cannot be reliably inferred from the standard octanol-water partitioning coefficient $\left(K_{o w}\right)$. In laboratory partitioning experiments, Martin et al. determined bioconcentration factors (BCFs) for rainbow trout exposed to a suite of PFCAs and PFSAs, and observed that their bioaccumulation potential was strongly related to perfluoroalkyl chain length and polar end group nature. ${ }^{8}$ Thereafter, in-situ measurement of bioaccumulation factors (BAFs $=$ concentration in biota relative to that of the surrounding water) corroborated that BAFs for PFCAs and PFSAs were positively correlated to perfluoroalkyl chain length. ${ }^{11-13}$ Concentrations in biota $>5000$ times those in water (i.e., Log BAF > 3.7) have been reported for PFOS and $\mathrm{C}_{10}-\mathrm{C}_{14}$ PFCAs, ${ }^{11,12,14}$ indicative of very bioaccumulative pollutants. ${ }^{15}$ Biotasediment accumulation factors (BSAFs = biota wet weight concentration relative to the sediment dry weight concentration) have also been documented, and ingestion of sediment is postulated as a major entry route for PFASs into benthic food webs. ${ }^{12,16-18}$

In addition to direct exposure to dissolved PFASs, the bioaccumulation of PFASs may occur via dietary uptake, which may be evaluated through the calculation of biomagnification factors (BMFs) (predator-prey concentration ratios), sometimes adjusted according to trophic level (BMFTL). ${ }^{19}$ Because of differences in biomass and contaminant transfer efficiencies, exponential models have been used to describe the increase of contaminant concentrations through entire food webs. ${ }^{19}$ Therefore, concentrations are usually Log-transformed prior to regression versus $\delta^{15} \mathrm{~N}$ or trophic level (TL), the antilog of the regression slope yielding the trophic magnification factor (TMF). ${ }^{19,20} \mathrm{TMFs}>1$ have been reported for long-chain PFAAs and perfluorooctane sulfonamide (FOSA), strongly suggesting biomagnification potential for these chemicals in aquatic ecosystems. ${ }^{17,21-26}$ However, given the wide range of TMF values observed across different food webs, the biomagnification of PFASs remains difficult to predict. Houde et al. have urged prudence in study designs, indicating an 
overt bias in BMF and TMF calculation when muscle tissue or liver or blood concentrations are used for larger species, while smaller biota species are analyzed as whole individuals or pooled homogenates. ${ }^{27}$ Because they increase the risk of selection biases, small sample sizes can greatly affect the conclusions drawn for studies regarding size- or sex-related PFAS levels in wildlife, ${ }^{27,28}$ but a similar comment could in fact apply to biomagnification studies. Even within a spatially and temporally integrated ecosystem, inherent biological variability in a species could lead to contaminant concentrations in some individuals to deviate substantially, which could obscure patterns. Another potential source of confusion lies in the varying abilities of organisms to metabolize PFOS-precursors (e.g., FOSA) and PFCA-precursors (e.g., fluorotelomer unsaturated carboxylates). Hence, the apparent biomagnification potential of PFOS and PFCAs may be inflated. ${ }^{11,22}$ Other common pitfalls that may affect the validity and reliability of TMFs have been extensively reviewed by Borgå et al. ${ }^{19}$

Albeit there exists no straight answer to such conundrums, the determination of TMFs could possibly be improved via appropriate study design and robust data treatment procedures. Uncertainties due to sampling design, analytical pitfalls, and statistical issues have been articulated in recent reviews, $19,27,29$ but some aspects remain yet to be addressed in practice. This constituted a first important knowledge gap to be explored. In the present work, several measures were initiated in an attempt to tackle various sources of uncertainty associated with the determination of biomagnification factors. A large set of biota samples ( $N=147 ; 18$ taxa) were collected in a spatially and temporally integrated aquatic ecosystem. PFAS concentrations were determined on a whole-body wet weight basis for all biota samples, thus avoiding the BMF/TMF uncertainties arising from different tissues/organs collected at different trophic levels. Original strategies were presented to simultaneously take into consideration left-censored data (non-detects) and the interspecific variability of PFAS levels and $\delta^{15} \mathrm{~N}$. Specific regression approaches based on linear mixed models accounting for censored responses were therefore implemented, involving functions from the NADA and LMEC R-packages. ${ }^{30}$ Rather than proposing definite answers to the question of PFAS trophic magnification, the overarching aim of the present study was to provide a practical approach for a more robust determination of TMFs, attempting to control sources of bias as much as possible. Another original contribution was the examination of PFAS trophodynamics in a typical temperate macrotidal estuary. Hitherto, PFAS trophodynamics have been essentially documented in marine ${ }^{22,24,25}$ or lake ${ }^{21,26,31}$ food webs, while dynamic estuarine systems have seldom been investigated. ${ }^{32}$ As noted by Borgå et al., the characteristics of ecosystems, including species composition, productivity, and latitude and longitude, may also exert effects in contaminant exposure and TMF. ${ }^{19}$ Estuaries typically present different biological and physical features from the previously studied ecosystems. The Gironde estuary (South Western France), the ecosystem under survey, presents a rather intricate trophic web structure, with two intertwined benthic and demersal sub-food webs. ${ }^{33}$ Most common predators in this food web are transient fish species - juveniles and sub-adult fish that reside within its waters before sexual maturation and migration offshore - and migratory fish species. The Gironde is a highly dynamic hydrosystem, subject to wide seasonal variations in freshwater discharge, salinity and sediment resuspension. It harbors an almost permanent maximum turbidity zone, stretching over several tens of kilometers, which may play a pivotal role in the exposure pathways of biota and in the sequestration of 
micropollutants. ${ }^{34,35}$ To our knowledge, this is the first time a PFAS trophic magnification study of such scope and comprehensiveness has been conducted in an estuarine ecosystem.

\section{Experimental}

\subsection{Chemicals and Standards}

A full list of chemicals and solvents is provided in the Supporting Information (SI). Certified PFAS native compounds and isotope-labelled internal standards (ISs) were acquired from Wellington Labs, Inc. (BCP Instruments, Irigny, France). The native PFASs targeted included PFCAs and PFSAs of various chain lengths, perfluorooctane sulfonamide (FOSA), N-alkylated sulfonamides (MeFOSA, EtFOSA) and $\mathrm{N}$-alkylated sulfonamide acetic acids (MeFOSAA, EtFOSAA). ${ }^{13} \mathrm{C}_{2}$-PFHxA, ${ }^{13} \mathrm{C}_{4}$-PFOA, ${ }^{13} \mathrm{C}_{2}$-PFDA, ${ }^{13} \mathrm{C}_{2}$-PFUnDA, ${ }^{13} \mathrm{C}_{2}$-PFDoA, ${ }^{13} \mathrm{C}_{4}$-PFOS, D3-N-MeFOSAA, ${ }^{13} \mathrm{C}_{8}$-FOSA, D ${ }_{3}-\mathrm{N}-\mathrm{MeFOSA}$, and $\mathrm{D}_{5}-\mathrm{N}-\mathrm{MeFOSA}$ were the isotope-labelled ISs used. Note that, in this paper, L-PFOS refers to the linear isomer of perfluorooctane sulfonate and Br-PFOS to the branched isomers (PFOS $=$ L-PFOS + Br-PFOS). In the case of Br-PFOS, the concentrations were calculated from the calibration curve used for the linear isomer (L-PFOS), and using a closely matched isotope-labelled IS $\left({ }^{13} \mathrm{C}_{4}\right.$-PFOS). Details on analyte names, acronyms, structures and corresponding ISs are enclosed in the SI (Table S1).

\subsection{Description of the study site}

Located on the French Atlantic coast, the Gironde estuary (SW France) is one of the largest in Europe (SI Fig.S1). This highly turbid environment is poorly conducive to photosynthesis; hence, detritus rather than phytoplankton is the base of the food web. ${ }^{36}$ The Gironde estuary is subject to high seasonal fluctuations of physicochemical factors (flow rate, salinity, temperature, tide, turbidity) and anthropogenic pressures. However, it is associated with high ecological production and a noteworthy and iconic biodiversity. ${ }^{36-39}$ The Gironde is of great ecological value: it is an important nursery ground for numerous marine fish species of the Bay of Biscay, a migratory corridor for several diadromous fish typical of Western Europe, and the last known natural breeding area of European sturgeon (Acipenser sturio). ${ }^{36}$ In the long run, synergistic effects of climatic change (e.g. temperature increase and salinization) and micropollutants may however durably affect biodiversity. ${ }^{40-44}$

\subsection{Sample Collection and Preparation}

A total of 147 biota samples were collected between May and November 2012 in the mesohaline zone of the Gironde estuary. Common seabass (Dicentrarchus labrax, $\mathrm{n}=9$ ), spotted seabass (Dicentrarchus punctatus, $\mathrm{n}=28$ ), grey mullet (Liza ramada, $\mathrm{n}=12$ ), meagre (Argyrosomus regius, $\mathrm{n}$ $=12$ ), anchovy (Engraulis encrasicolus, $n=6$ ), sprat (Sprattus sprattus, $n=3$ ), common sole (Solea solea, $n=31$ ) and flounder (Platichthys flesus, $n=13$ ) samples were collected by bottom trawling or dragnet fishing. ${ }^{39}$ In parallel, Copepods (Copepoda, ind.), mysids (Mysidacea, ind.), white shrimps 
(Palaemon longirostris), brown shrimps (Crangon crangon), gammarids (Gammarus spp.) and gobies (Pomatoschistus spp.) were collected with a cone-shaped WP-2 net (mesh: $200 \mu \mathrm{m}$ ). Other benthic invertebrates were collected at low tide along intertidal mudflats of the southern ( $S^{t}$ Christoly) and northern banks (Talmont-sur-Gironde, Mortagne) of the estuary (SI Fig.S1).

Fish samples were weighed and measured prior to dissection. All biota samples were freeze-dried (72 h) and ground. Note that small fish and invertebrates were prepared as pooled whole-body homogenates, while muscle tissues were processed for larger fish $(>100 \mathrm{~mm})$. Therefore, a correction factor was determined and used to convert PFAS muscle concentrations into whole-body (w-b) concentrations. The conversion factor generally ranged between 2-3, consistent with previous observations (SI Table S2). ${ }^{32}$

Further details regarding the collection and handling of water and sediment samples are provided in the SI.

\subsection{PFAS Chemical Analyses}

Analytes were quantified using the isotopic dilution method, ISs being gravimetrically added to the samples, procedural blanks and reference materials at the beginning of the extraction procedure. Briefly, water samples $(0.5 \mathrm{~L})$ were concentrated using solid phase extraction on Strata X-AW cartridges, while sediment samples $(1 \mathrm{~g})$ underwent a microwave extraction with $\mathrm{MeOH}$ prior to ENVICarb graphite clean-up. ${ }^{45}$ Biota samples ( $250 \mathrm{mg}$ dry weight $(\mathrm{dw})$ ) were processed using a microwave extraction with ethanol followed by Strata X-AW/graphite clean-up. ${ }^{46}$

PFAS chemical analyses were performed with an Agilent 1200 LC system interfaced with an Agilent 6460 triple quadrupole mass spectrometer (Agilent Technologies, Massy, France). Analyte separation was achieved with a Zorbax Eclipse Plus C18 column using chromatographic conditions described in the SI. Further details on mass spectrometry acquisition parameters are provided elsewhere. ${ }^{45}$

Limits of detection (LODs) were determined as described elsewhere ${ }^{45}$ and were in the range $0.003-$ $0.3 \mathrm{ng} \mathrm{L}^{-1}, 0.001-0.1 \mathrm{ng} \mathrm{g}^{-1} \mathrm{dw}$ and $0.002-0.05 \mathrm{ng} \mathrm{g}^{-1}$ wet weight $(\mathrm{ww})$ for surface water, sediment and biota samples, respectively (SI Table S3). Due to the low expected concentration of short-chain $\left(\mathrm{C}_{4-}\right.$ $\mathrm{C}_{6}$ ) PFCAs in sediments or biota and their background presence in corresponding procedural blanks, the latter were measured only in water samples.

Whole-method recovery was controlled through replicate analyses of mineral water samples (fortified at $1 \mathrm{ng} \mathrm{L}^{-1}$ ), reference sand samples (fortified at $1 \mathrm{ng} \mathrm{g}^{-1} \mathrm{dw}$ ) and brown trout fillets from the Kerguelen archipelago (Southern Ocean) (fortified at $3 \mathrm{ng} \mathrm{g}^{-1} \mathrm{ww}$ ), and ranged between 53-134\%, 56-86 \% and 51-107\% for the water, sediment, and biota matrices, respectively (SI Tables S4-S6). Whole-method accuracy was determined using mineral water, reference sand and brown trout spiked samples (supplemented with both native analytes and ISs at the start of the preparation procedure) and remained generally between $80-120 \%$ (SI Tables S4-S6). Additionally, a non-spiked spotted seabass sample (dorsal muscle) was used as an in-house control matrix; the relative standard 
deviation of PFAS concentrations determined in this matrix averaged $6 \%$ (range: 1.8-18\%) (SI Table S7). Matrix effects were evaluated by comparing solvent-based analyte to internal standard area ratios to those of brown trout extracts spiked post-preparation, corrected by the non-spiked sample initial contribution. ${ }^{47}$ Method trueness was controlled through the analysis of NIST SRM 1947 reference samples $(n=4)$ (Lake Michigan Fish Tissue) (SI Table S7). The concentrations determined for PFOS and PFCAs were in excellent agreement with previous reports. ${ }^{31,48,49}$

\subsection{Stable Isotope Analyses}

To determine the isotopic compositions of biota samples ( $\mathrm{C}$ and $\mathrm{N}$ ), freeze-dried biota samples were ground into fine and homogeneous powder with a micro ball mill $(25 \mathrm{~Hz})$ and lipids subsequently extracted by accelerated solvent extraction. ${ }^{50}$ Samples were weighed $(0.2 \pm 0.1 \mathrm{mg})$ in tin capsules and stable isotope ratios determined using a Thermo Finnigan Delta V EA-IRMS (Elemental Analyzer - Isotope Ratio Mass Spectrometry) with a Conflo IV interface. Carbone and nitrogen isotope compositions were expressed as per mil $(\%)$ in the $\delta$ notation relative to Vienna PeeDee Belemnite (vPDB) and atmospheric $\mathrm{N}_{2}$, respectively. Isotopic analyses were performed in triplicate for each biota sample and standard deviations remained in the range $0.03-0.23 \%$ for $\delta^{15} \mathrm{~N}$. Every $10-15$ analyses, IAEA-N2 $\left(\delta^{15} \mathrm{~N}=20.3 \%\right)$ and USG-24 $\left(\delta^{13} \mathrm{C}=-16.1 \pm 0.2 \%\right)$ reference materials were run to control for analytical drift, and averaged $20.59 \pm 0.07 \%(n=15)$ and $-15.82 \pm 0.26 \%(n=28)$, respectively. $\delta^{15} \mathrm{~N}$ and $\delta^{13} \mathrm{C}$ values of an in-house control mussel matrix averaged $13.57 \pm 0.18 \%$ and $-14.18 \pm$ $0.17 \%$, respectively (multibatch replicate measurements, $n=9$ ) (quality control chart provided in Fig.S2 of the SI).

\subsection{Determination of Trophic Levels and TMFs}

Trophic levels were calculated according to the formula for two food source: $T L=\lambda+\left[\delta^{15} N_{\text {consumer }}-\{\alpha\right.$ $\left.\left.\delta^{15} N_{\text {base } 1}+(1-\alpha) \delta^{15} N_{\text {base2 }}\right\}\right] / \Delta_{n}$, where $\lambda$ is the estimated trophic position of the organism at the base of the food web (for primary consumers, $\lambda=2$ ), $\delta{ }^{15} \mathrm{~N}_{\text {base1 }}$ and $\delta^{15} \mathrm{~N}_{\text {base2 }}$ are the mean $\delta^{15} \mathrm{~N}$ of the baseline organisms for the benthic and demersal food webs, respectively, and $\Delta_{n}$ is the mean trophic fractionation of $\delta^{15} \mathrm{~N}$ across two successive trophic levels $\left(\Delta_{n}=3.4 \%\right.$, as per Post). ${ }^{51} \alpha$ is a coefficient used to adjust the relative importance of each nitrogen food source for a given consumer, derived in our case from the known feeding ecology of fish from the Gironde estuary food web (see Table S8 of the SI). ${ }^{33}$ For all the fish taxa considered, it was deemed acceptable to consider that the benthic and intermediate pelagic sources were the major food sources, since the contribution of other sources to the diet (i.e., detritic or phytoplanktonic sources) remained below $15 \%$ on average. ${ }^{33} \mathrm{In}$ the case of zooplankton, small pelagic fish (anchovy, sprat) and shrimps, a was set at 0 , while benthic invertebrates (ragworm, shore crab and gammarids) were assigned the value of $\alpha=1$.

The $R$ statistical software ( $R$ version 2.15.3, R Core Team, 2013) and Sigmaplot ${ }^{\mathrm{TM}} 11.0$ (Systat Software) were used to conduct data analysis. Statistical significance was set at $p<0.05$. In view of the presence of non-detect data, functions from the NADA (Non-detects And Data Analysis) and LMEC (Linear Mixed-Effects Models with Censored Responses) R-packages were used to perform 
regression analyses. Logarithm-transformed PFAS concentrations were plotted against trophic level, the TMF being subsequently obtained as $10^{\text {slope }}$.

Two regression approaches were considered in parallel. The cenken function (NADA) imputes nondetects based on the distribution of observed data prior to determination of the Akritas-Theil-Sen (ATS) line (slope, intercept, and Kendall's t nonparametric correlation coefficient). In an attempt to consider non-detect data as well as inter-species variability of $\delta^{15} \mathrm{~N}$ and PFAS levels (random effects), we used a linear mixed effect model with censored responses, implemented in $\mathrm{R}$ via the function Imec. 30 The latter model was as follows: Log Concentration $=\sim T L+(1 \mid$ Species $)$, i.e. a standard linear regression between log concentration and trophic level, but including a random effect on species. This approach should also account for the TMF distortion due to differences in number of samples between taxa (e.g. $\mathrm{N}_{\text {spotted seabass }}>\mathrm{N}_{\text {sprats }}$ ) (see also Table $\mathbf{S} 10$ of the SI). Scripts for the cenken and Imec procedures are provided in the SI. Statistically significant biomagnification (i.e. TMF $<1$ or $>1$ ) was based on the $\mathrm{p}$-value for the cenken procedure (i.e. $\mathrm{p}<0.05$ ), while the criterion examined for the Imec procedure was based on the $95 \%$ confidence interval (i.e. the $95 \%$ confidence interval associated to the slope of the regression should not include the zero value). Also note that compounds with more than $80 \%$ censored observations were not considered in the determination of TMFs since tenuous statistics may be obtained above this threshold. 


\section{Results and discussion}

\subsection{Trophic Levels}

The Gironde estuary is characterized by two intertwined sub-food webs, a benthic food web mainly composed of flat fish (sole, flounder), endobenthic invertebrates (polychaetes, clams), and epibenthic crustaceans (shore crab, gammarids), and a bentho-pelagic ('demersal') food web dominated by top predators (seabass, meagre) that may feed on both intermediate pelagic (e.g., zooplankton, shrimps, small pelagic and juvenile fish) and benthic food sources. ${ }^{33}$ Individual $\delta^{15} \mathrm{~N}$ values were in the range $5.1-15.4 \%$. Mean $\delta^{15} \mathrm{~N}$ values of the ichthyofauna were in the following order: meagre $\sim$ common seabass $\sim$ spotted seabass $>$ sole $>$ flounder $>$ mullet $\sim$ sprat $\sim$ goby $>$ anchovy (SI Fig.S3), in good agreement with Pasquaud et al. ${ }^{33,52}$ Oysters and scrobicularidae displayed consistently low $\delta^{15} \mathrm{~N}(7.7$ \pm 1.1 and $7.3 \pm 1.1 \%$, respectively) and were used as baseline organisms (TL $=2$ ) for the determination of TLs of higher-level consumers (see also Section 2.6).

\subsection{PFAS concentrations in Surface Water and Sediments}

Among the 23 PFASs analyzed, 15 were detected in surface water samples $(n=6)$. $\Sigma$ PFASs ranged between 4.2-7.9 $\mathrm{ng} \mathrm{L}^{-1}$, individual compounds generally remaining at sub $\mathrm{ng} \mathrm{L}^{-1}$ levels (SI Table S9). PFOS prevailed over other PFASs ( $23 \pm 3 \%$ of $\Sigma$ PFASs), followed by $\mathrm{C}_{5}-\mathrm{C}_{8}$ PFCAs (between $8-15 \%$ each) and PFHxS ( $8 \pm 1 \%)$. In sediment samples $(n=5), 18 / 20$ PFASs were detected. With an average $\Sigma$ PFASs of $1.2 \pm 0.3 \mathrm{ng} \mathrm{g}^{-1} \mathrm{dw}$, levels in sediments remained in the same order of magnitude than those reported at French nationwide scale (mean $\Sigma$ PFASs $=1.8 \mathrm{ng} \mathrm{g}^{-1} \mathrm{dw}$ ). ${ }^{45}$ The highest level of PFAS in sediments was that of PFOS $\left(0.38 \pm 0.11 \mathrm{ng} \mathrm{g}^{-1} \mathrm{dw}\right)$, followed by $\mathrm{C}_{8}-\mathrm{C}_{12}$ PFCAs $(0.077 \pm$ 0.030 to $0.13 \pm 0.037 \mathrm{ng} \mathrm{g}^{-1} \mathrm{dw}$ ) (SI Table S9).

\subsection{PFAS Levels and Composition Profiles in Biota}

Overall detection frequencies and concentration ranges of PFASs in biota are reported in Table 1, and the mean EPFASs across taxa is illustrated in Fig.1 (see also Table S10 of the SI for concentration ranges of individual PFASs and $\Sigma$ PFASs for each species). 


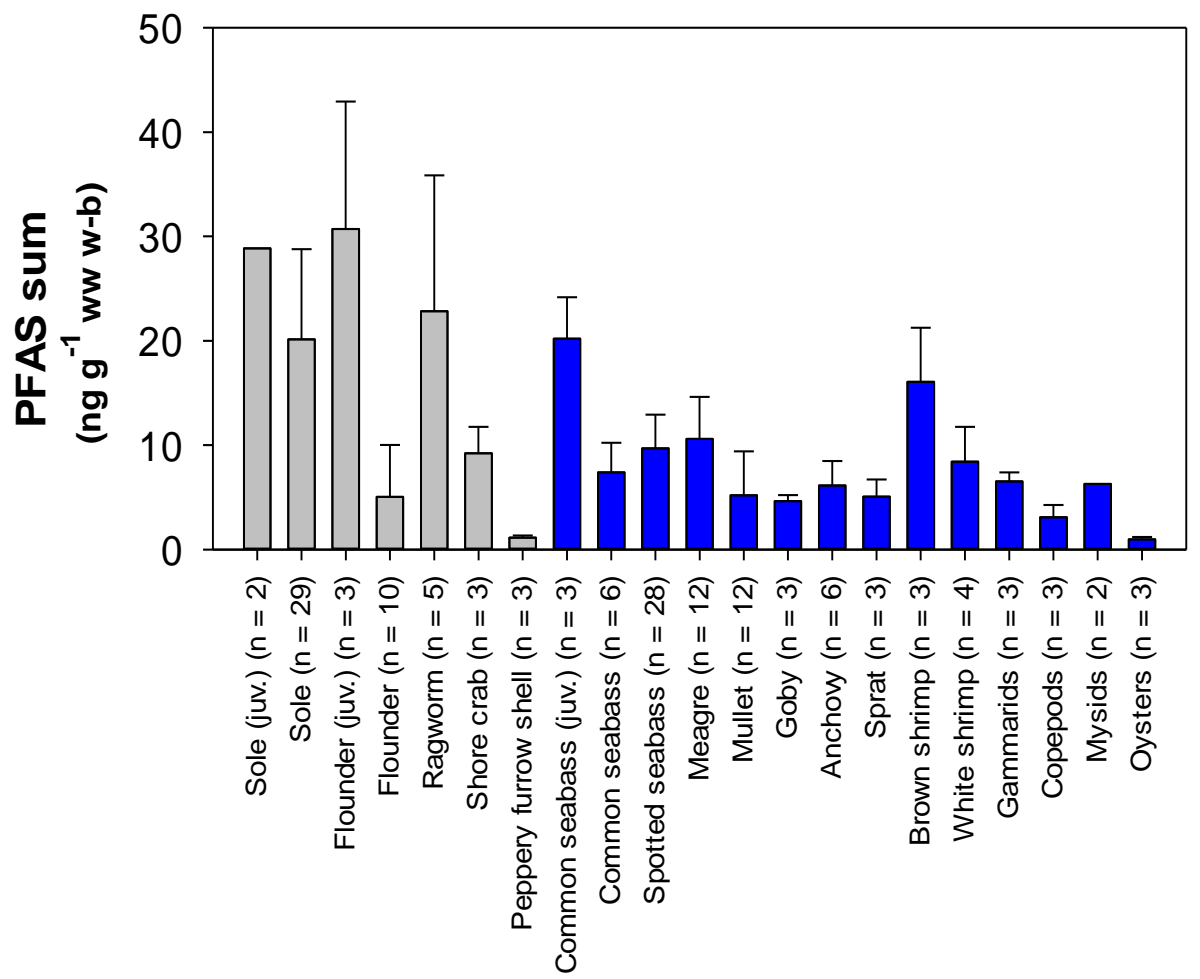

Fig.1. Mean total PFAS concentrations (LPFASs) in fish and invertebrates from the Gironde estuary (grey bars: benthic food web; blue bars: demersal food web). Concentrations are expressed in $\mathrm{ng} \mathrm{g}^{-1}$ wet weight $(w w)$ whole-body ( $w-b)$ (juv. = juveniles). Error bars correspond to standard deviation.

In biota samples $(n=147)$, L-PFOS and FOSA displayed the highest detection frequencies (DF) (100 $\%$ ), and $\mathrm{C}_{9}-\mathrm{C}_{13}$ PFCAs were almost systematically detected (DF $=86-95 \%$ ). Average $\Sigma$ PFASs in fish were in the range 4.6-20.7 $\mathrm{ng} \mathrm{g}^{-1} \mathrm{ww} w-b$, a moderate burden compared to concentrations reported in some Canadian lakes, ${ }^{21,31}$ but in the same order of magnitude than total concentrations in fish from Sarasota Bay (Florida, USA) and Mai Po Marshes (Hong Kong, China). 17,23 PFAS concentrations in juveniles of flounder (length $=25-95 \mathrm{~mm}$; $\Sigma$ PFASs range $=20-44 \mathrm{ng} \mathrm{g}^{-1} \mathrm{ww} w-b$ ) were significantly higher than those in larger specimens (length $=140-340 \mathrm{~mm}$; median $\Sigma$ PFASs $=3.7 \mathrm{ww} w$-b). In addition, for both common sole and spotted seabass, a negative linear relationship was observed between $\sum$ PFASs and length ( $R^{2}: 0.23-0.43, p<0.01$ ). This is concordant with Lescord et al. who reported mean $\Sigma$ PFASs between 1.5-4.3 times higher in juvenile Arctic char (Salvelinus alpinus) than in adult char at $4 / 6$ Canadian lake sampling sites. ${ }^{31} \mathrm{~A}$ significant decreasing trend of $\Sigma$ PFASs with increasing age was also observed in bottlenose dolphins from southeast US estuaries. ${ }^{53}$ Lower PFAS concentrations in adults compared to juveniles are possibly a consequence of growth dilution and changes in diet or metabolic rates with increasing age. A plausible additional explanation in our specific case might lie in the different life traits displayed by juveniles of fish that remain confined to the estuarine area; they might therefore be subject to enhanced PFAS exposure compared to larger subadult specimens that may occasionally venture into offshore coastal waters. Median $\Sigma$ PFAS levels in sole (20.4 $\mathrm{ng} \mathrm{g}^{-1} \mathrm{ww}$ w-b) were nearly two-fold higher than those in pelagic fish (9.3, 9.6 and $10 \mathrm{ng}$ $\mathrm{g}^{-1} \mathrm{ww} \mathrm{w}-\mathrm{b}$ for common seabass, spotted seabass and meagre, respectively). Relatively high PFAS 
levels were also found in the endobenthic polychaete Nereis diversicolor compared to other invertebrates, $\Sigma$ PFASs reaching up to $45 \mathrm{ng} \mathrm{g}^{-1} \mathrm{ww} w$-b. This concurs with previous observations by Nakata et al. who also reported elevated LPFASs in lugworms Arenicola marina from the Ariake Sea food web ( $\Sigma$ PFASs $\sim 80 \mathrm{ng} \mathrm{g}^{-1} \mathrm{ww} \mathrm{w}$-b), greatly exceeding those in bivalves or crabs. ${ }^{16}$ PFASs are relatively water soluble, which could promote direct exposure of biota. However, taken together, the above findings further suggest that the ingestion of sediments may play a critical role in PFAS accumulation for sediment-dwelling organisms. Low total PFAS concentrations were observed in oyster and peppery furrow shell, LPFASs ranging between $0.66-1.2$ and $0.89-1.3 \mathrm{ng} \mathrm{g}^{-1} \mathrm{ww}$ w-b, respectively, in excellent agreement with So et al. ${ }^{54}$ The low bioaccumulation potential of PFASs in filter-feeders may be a result of overall low affinity binding (reversible uptake), while elimination of the higher affinity binding PFAS fraction might be mediated via multixenobiotic resistance transporter proteins. ${ }^{55}$

L-PFOS was generally the dominant PFAS in biota, albeit with some species-specific characteristics (SI Fig.S4). In pelagic organisms, L-PFOS represented $49 \pm 11 \%$ of $\Sigma$ PFASs on average, followed by FOSA and PFDA (18 $\pm 14 \%$ and $6.7 \pm 4 \%$ of $\Sigma$ PFASs, respectively), while long-chain PFCAs $\left(\mathrm{C}_{11-}\right.$ $\mathrm{C}_{14}$ ) were less prominent $(0.5-3.7 \%$ of $\Sigma$ PFASs each, on average). The congener patterns observed are in excellent agreement with previous reports. ${ }^{21,23,24}$ Overall moderate PFOS levels were observed in fish: fillet concentrations in species of fishery interest remained below the current environmental quality standard set by the European Union ( $E Q S_{\text {biota }}=9.1 \mu \mathrm{g} \mathrm{kg}^{-1} \mathrm{ww}$ ) (Directive 2013/39/EU), except for one exceedance (SI Fig.S5). In gammarids, PFOA was the second most abundant congener after L-PFOS (15 $\pm 15 \%$ Vs $32 \pm 8 \%$ of $\Sigma$ PFASs), akin to patterns reported for Gammarus wilkitzkii from the Barents Sea. ${ }^{56}$ The relative abundance of FOSA invariably exceeded that of L-PFOS in oysters (74 $\pm 7 \%$ Vs $12 \pm 7 \%$ of $\sum$ PFASs). This distinctive pattern is consistent with profiles observed in shellfish from the Seine and Loire estuary (France), ${ }^{57}$ green-lipped mussels Perna viridis from the Chinese coast, ${ }^{54}$ and mussel standard reference material SRM 2974a, ${ }^{48}$ and could be related to the lower metabolic capacity of filter-feeding bivalves as regards the biotransformation of PFOSprecursors such as FOSA.

In order to investigate the influence of life traits (e.g., benthic Vs demersal) on PFAS accumulation profiles, it has been previously suggested to examine PFOA/PFOS concentration ratios. ${ }^{16}$ In our case, this approach could not be implemented as such due to the lower detection frequency of PFOA (63\%) relative to L-PFOS (100\%). Instead, we attempted to consider PFNA and FOSA Vs L-PFOS, compounds of low censoring percentages (0-9\%). Average PFNA/L-PFOS concentration ratios in flatfish were 1-2 orders of magnitude higher than those of pelagic fish. Likewise, benthic invertebrates showed relatively high PFNA/L-PFOS ratios $(2.0 \pm 1.0$ and $0.58 \pm 0.28$ for ragworm and shore crab, respectively) compared to other invertebrates (Fig.2). This is consistent with Nakata et al. who observed higher PFOA/PFOS ratios in tidal flat organisms than those from shallow water. ${ }^{16}$ Another similarity between ragworm and shore crab was the prevalence of other PFCAs: these species were the only ones with concentrations of PFHpA above $1 \mathrm{ng} \mathrm{g}^{-1} \mathrm{ww} w-b$, and had the highest PFOA/LPFOS concentration ratios ( $1.4 \pm 0.6$ and $0.94 \pm 0.08$ for ragworm and shore crab, respectively). 
Previous laboratory and field studies have demonstrated that FOSA and related derivatives could biotransform to PFOS, for instance via microbially-mediated transformation in soils or sediments $\mathbf{5 8 , 5 9}$ as well as via ingestion and in vivo metabolization in higher order organisms. ${ }^{60}$ Galatius et al. reported a high degree of variability of FOSA to PFOS ratios across marine mammal species. ${ }^{61}$ Possible explanations include different metabolic capacities ${ }^{61,62}$ as well as differences in exposures between distant sampling locations or over time as regulations regarding PFOS and related precursors come into effect. ${ }^{63}$ In the present survey, the samples were collected within a relatively short period of time and over a geographically limited area; this could have contributed to limit the interspecific variability of precursors/PFAA ratios. In most organisms from the present survey, FOSA/L-PFOS ratios were $<1$ (Fig.2b), concurring with previous observations by Martin et al. in a Lake Ontario food web. ${ }^{21}$ Average FOSA/L-PFOS concentration ratios did not span more than 2 orders of magnitude, with maximum values for oysters (7.4) and sprats (6.9) and minimum values for benthic fish and crabs $(0.080-0.15)$ (Fig.2b). When examining each food web separately, it was apparent that FOSA/L-PFOS ratios remained within a rather consistent range of values for all taxa (i.e. both invertebrates and fish). For the demersal food web for instance, even when excluding the two outliers (i.e. oysters and sprats), no significant difference in mean FOSA/L-PFOS ratios was detected between invertebrates and fish. In the absence of clear differences between invertebrates and fish for each food web, it was hypothesized that biotransformation of FOSA at different metabolic rates between species would not play a major role in the transfer of PFOS in the Gironde estuary food webs. While the four other FOSA-related compounds were not preponderant in water, sediment, or biota samples, the possible contribution of other PFAA precursors (not targeted in the present survey) could not entirely be ruled out. 

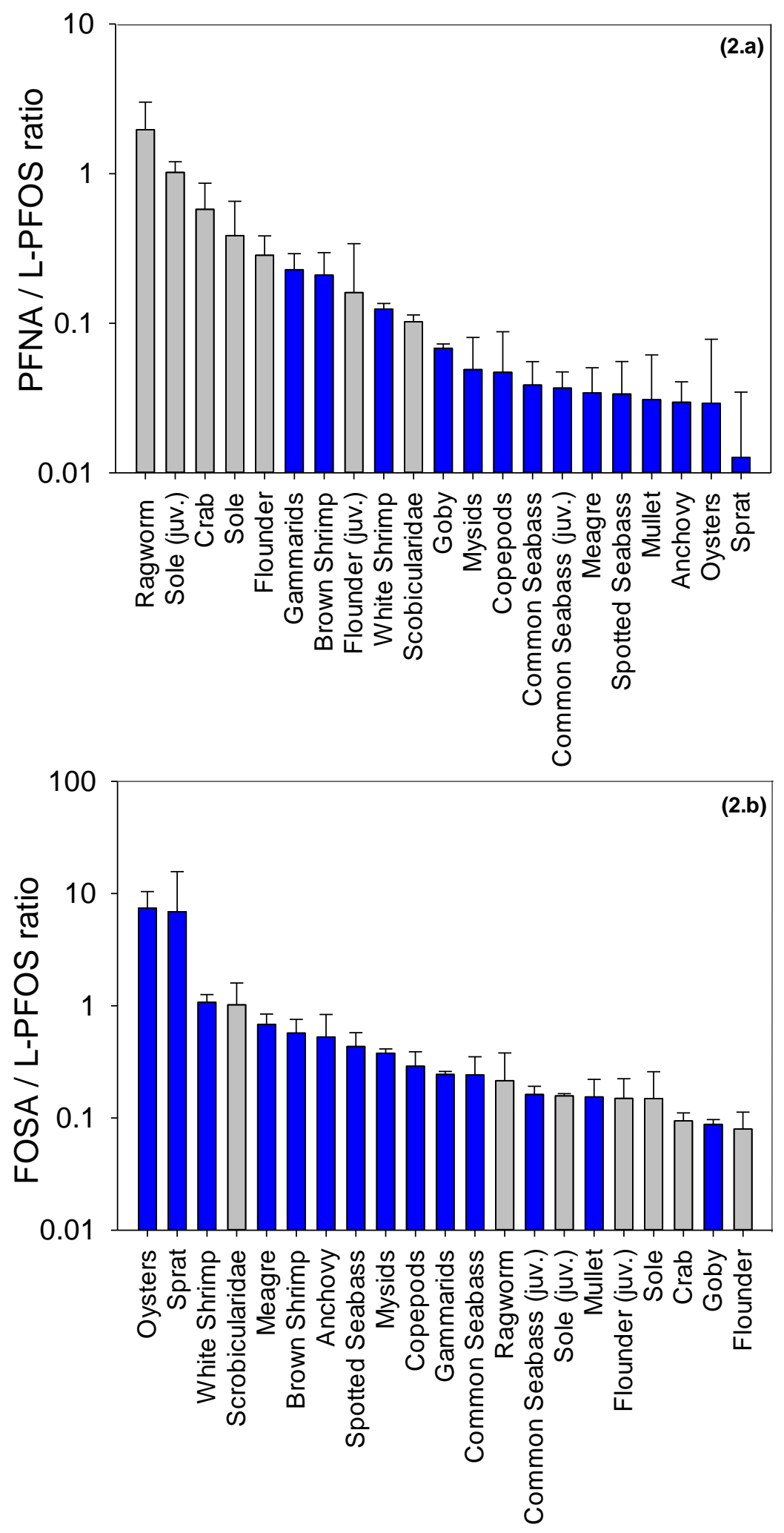

Fig.2. Evolution of the PFNA / L-PFOS (2.a) and FOSA / L-PFOS (2.b) concentration ratios across biota species collected in the Gironde estuary (juv. = juveniles). Grey bars: benthic food web; blue bars: demersal food web. 


\subsection{Bioaccumulation}

Regardless of taxa, average BAFs were consistently high for FOSA (7430-151200), followed by PFUnDA (1030-54400), L-PFOS (122-7490) and PFDA (89-7370), while those of shorter-chain compounds were sensibly lower (e.g., 9.5-697 and 20-1250 for PFHxS and PFOA, respectively) (SI Table S11). This again underscores the importance of perfluoroalkyl chain length and polar end group nature on PFAS bioaccumulation. For $\mathrm{C}_{8}-\mathrm{C}_{11}$ PFCAs (i.e. PFCAs bearing 7-10 perfluoroalkyl carbon atoms), Log BAF evolved in a linearly fashion with perfluoroalkyl chain length, each additional $-\mathrm{CF}_{2}$ moiety contributing to an increase of $0.59 \pm 0.10$ log units (slope range for the different taxa considered: $0.45-0.77$ ), in reasonable agreement with previous reports. ${ }^{11-13}$

With the notable exception of Scrobicularidae, BSAFs did not follow the linear chain-length dependency in the benthic food web. Higher values were actually observed for PFNA and PFDA than for $\mathrm{C}_{11}-\mathrm{C}_{14}$ PFCAs, or for PFHxS than for PFOS (SI Table S12). For instance, BSAFs in Nereis diversicolor were consistently high for PFNA $(B S A F=61 \pm 15)$ and increased linearly from PFHpA to PFNA ( 23 on average for each additional $-\mathrm{CF}_{2}$ ), while those of long-chain PFCAs $\left(\mathrm{C}_{11}-\mathrm{C}_{14}\right)$ were in the narrow range 1.2-5.5 on average. Similar trends were observed in a bioaccumulation experiment under controlled laboratory conditions, the BSAFs of the oligochaete Lumbriculus variegatus being significantly higher for $\mathrm{C}_{8}-\mathrm{C}_{10}$ PFCAs than for $\mathrm{C}_{11}-\mathrm{C}_{12}$ PFCAs, verified in organisms exposed to either spiked or non-spiked sediments. ${ }^{64}$ As discussed in Higgins et al., the relatively high bioaccumulation of PFNA in worms might be a consequence of a lower elimination rate constant of this compound. ${ }^{64}$ The distinctive BSAF patterns of Scrobicularidae may be related to different exposition pathways: Scrobicularidae are deposit-feeders while ragworms can alternate between predation, deposit-feeding and filter-feeding. ${ }^{65}$

\subsection{Food Web Biomagnification}

It has been previously hypothesized that biological variables such as different protein content could be an influential factor of BMF and TMF estimation for proteinophilic contaminants such as PFASs, ${ }^{27,29}$ while other components, such as phospholipids, could also play a role in PFAS uptake. ${ }^{66}$ Protein normalization of PFAS concentrations, although infrequently applied, ${ }^{24}$ may be useful when different tissues/organs are collected at different trophic levels. In the present study, the trophic level span was typically shorter than in previous studies and concentrations were determined on a whole-body wet weight basis for all biota samples. Additionally, the interspecific protein content of crustaceans and a large number of fish species from the adjacent Bay of Biscay has been shown to vary within a rather limited range $(\sim 15-20 \% w w) .{ }^{67}$ In view of the aforestated, we did not attempt at normalizing PFAS concentrations to protein levels for bioaccumulation and biomagnification assessment.

Predator-prey biomagnification factors (BMFs) were calculated by dividing the pollutant concentration in the predator by the mean of that of its prey. Mean BMFs were generally $>1$ for L-PFOS (Fig.3), FOSA, and long-chain PFCAs, suggesting biomagnification (see also Table S13 of the SI). Likewise, BMFs corrected for trophic level $\left(B^{\prime} F_{T L}\right)$ were also often $>1$ (SI Table S14). 
Trophic magnification factors (TMFs) could be more reliable indicators than BMFs since the concentration of contaminants is examined across food webs through a continuous $x$-variable such as $\delta^{15} \mathrm{~N}$ or TL, contrary to BMFs that are typically examined for exclusive predator-prey couples (a rather unrealistic assumption). However, inconsistent results may still be obtained for TMFs if study design and data treatment are not appropriately addressed. ${ }^{19}$ These include, for instance, the choice of the organism for the baseline of the food web, seasonal variations in contaminant levels or $\delta^{15} \mathrm{~N}$ (especially for lower TLs), analytical considerations such as matrix effects, and data analysis such as the importance of the statistical treatment of non-detects (data $<$ LOD).

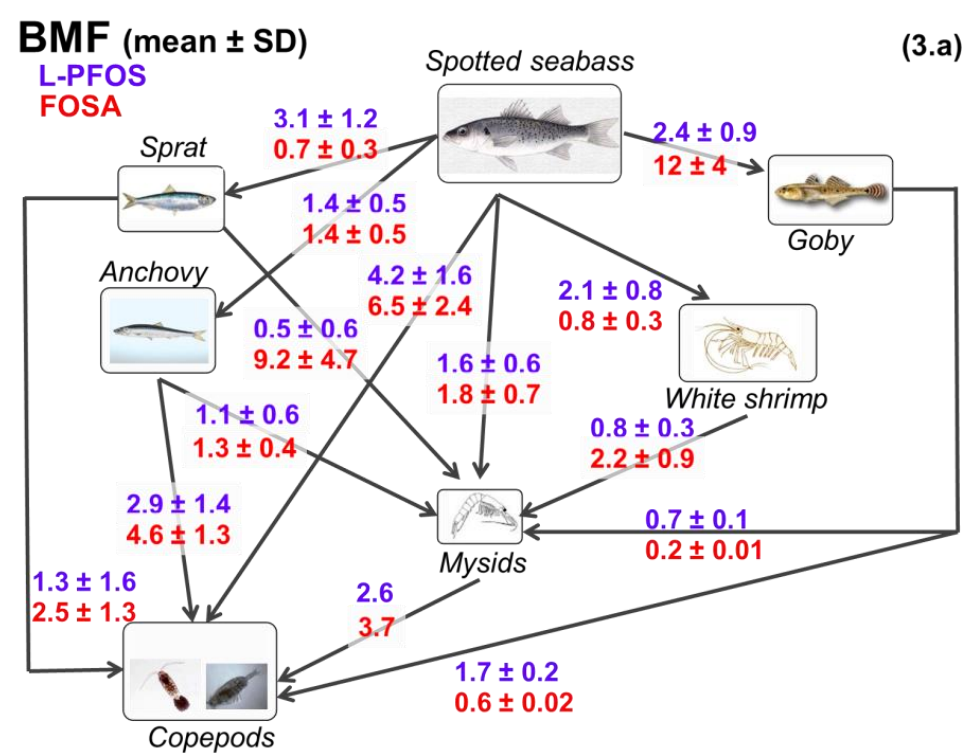

\section{BMF (mean \pm SD)}

(3.b)

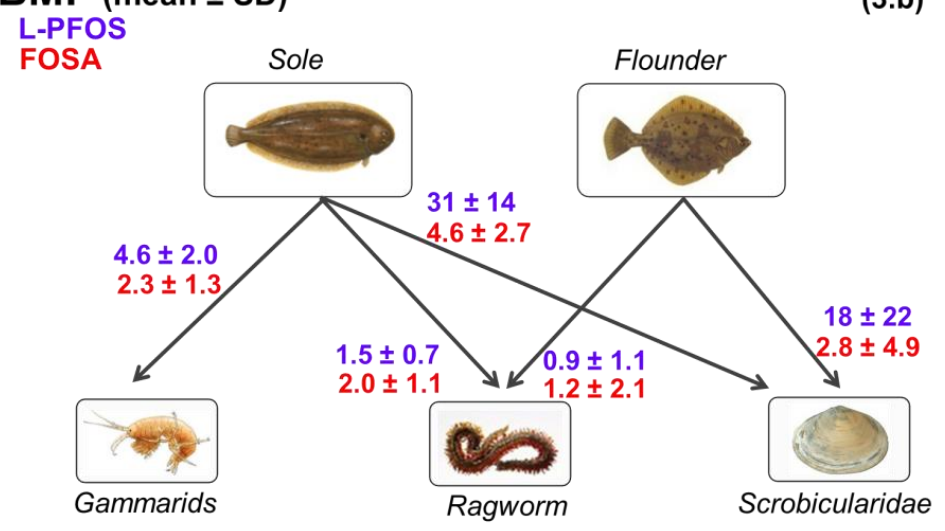

Fig.3. Illustration of the biomagnification factors (BMFs) (mean \pm standard deviation) of L-PFOS (blue font) and FOSA (red font) in a demersal (3.a) (not shown: meagre A. regius, common seabass $D$. labrax) and benthic (3.b) Gironde estuary food web.

In the present study, TLs were determined based on the formula for two food sources, referring to the two dominant food webs in the system. In the case of higher-order consumers, the coefficients for 
each baseline $\delta^{15} \mathrm{~N}$ were adjusted according to relative percentage diet compositions (Section 2.6). It was documented that PFAS levels and profiles remained relatively stable at the water-year scale in water, sediment and biota (i.e. maximum/minimum concentration ratio $<2.5$ in water or zooplankton) (unpublished data). Therefore, the fact that sampling was spread over a five-month period should not have excessively affected TMFs. Differing matrix effects between samples may possibly lead to inaccurate quantitation and hence bias the determination of TMF. The use of adequate isotopelabelled ISs (added prior to extraction) can to some extent compensate for variable recovery and matrix effects between samples. In our case, low to moderate matrix effects were obtained regardless of analyte concentration over the tested range (SI Table S15). This was achieved by combining a relatively small sample size $(250 \mathrm{mg})$, efficient purification, and isotopic dilution using matched or closely-matched isotope-labelled ISs for all target analytes (Section 2).

It has been also suggested that the substitution of non-detects by a single arbitrary value (e.g., $0.5 \mathrm{x}$ LOD or DF $x$ LOD), although a rather common practice, has no theoretical basis and may lead to poor correlation estimates. ${ }^{68}$ To circumvent this, more statistically robust methods have been developed, wherein a lognormal distribution is usually fitted to the data set prior to the imputation of unknown observations. ${ }^{68}$ In the case of PFUnDA in the intermediate demersal food web, for instance, relatively high TMFs were generated when using a substitution by $0.5 \times$ LOD or DF $\times$ LOD $\left(p<0.0001 ; R^{2}=\right.$ 0.23-0.24; TMF = 3.2-3.7) (Fig.4), while an alternative technique such as the Akritas-Theil-Shen estimator (cenken function) suggested a non-significant relationship $(p=0.08$; Kendall's $\mathrm{T}=0.13$; slope $=0.15 ; \mathrm{TMF}=1.4$ ). The conclusions were similar when applying a linear mixed effect model with censored responses, the regression slope returned by the Imec function being non-significantly different from 0 ( $0.86 \leq$ TMF $\leq 1.01)$ (Fig.4). This again shows that the use of substitution, even at low censoring percentages $(<12 \%$ non-detects for PFUnDA in the intermediate demersal food web), leads to such a distortion of TMFs that conflicting conclusions can be drawn.

The regressions between TL and the logarithm of PFAS concentrations (wet weight whole-body basis) using Imec yielded TMFs in the range $0.18-1.5$ and $0.33-6.0$ for the demersal and benthic food webs, respectively (Table 1). Note that analogous results were produced with cenken (SI Table S16). TMFs for all taxa combined $(\mathrm{N}=147)$ are also provided (SI Table S17) and revealed significant biomagnification for $\mathrm{C}_{8}-\mathrm{C}_{12}$ PFCAs, PFHxS, PFOS and FOSA. In the demersal food web, TMFs were significantly $>1$ for PFDoDA, PFHxS, Br-PFOS and FOSA (TMF range: 1.2-1.5), while those of other PFCAs were in the range $0.88-1.2$ and that of L-PFOS significantly $<1$ (TMF $=0.94$ ). These findings differ from lacustrine or coastal food webs from Northern America (e.g., TMFpFos $=5.8-6.3$ ), ${ }^{21,23}$ but are not dissimilar to those reported in some freshwater food webs from China. ${ }^{17,26}$ The former are typically longer food webs, dominated by mammals and spanning over 4 TLs (Vs 2.7 TLs in the present study). In contrast to air-breathing organisms, fish may be endowed with more efficient PFAS elimination via gill excretion, ${ }^{24}$ which could explain the lower TMFs reported in the present study and in those of Loi et al. (TMFPFOS $=1.3$; TMF TFUnDA $=1.7$ ) or Lescord et al. (TMFs $\leq 1$ ) where fish and not mammals were the apex predators of the food web. ${ }^{17,31}$ In addition to food web structure, differences 
in TMFs among studies may be related to differences in study design and calculation methodology. 19,29
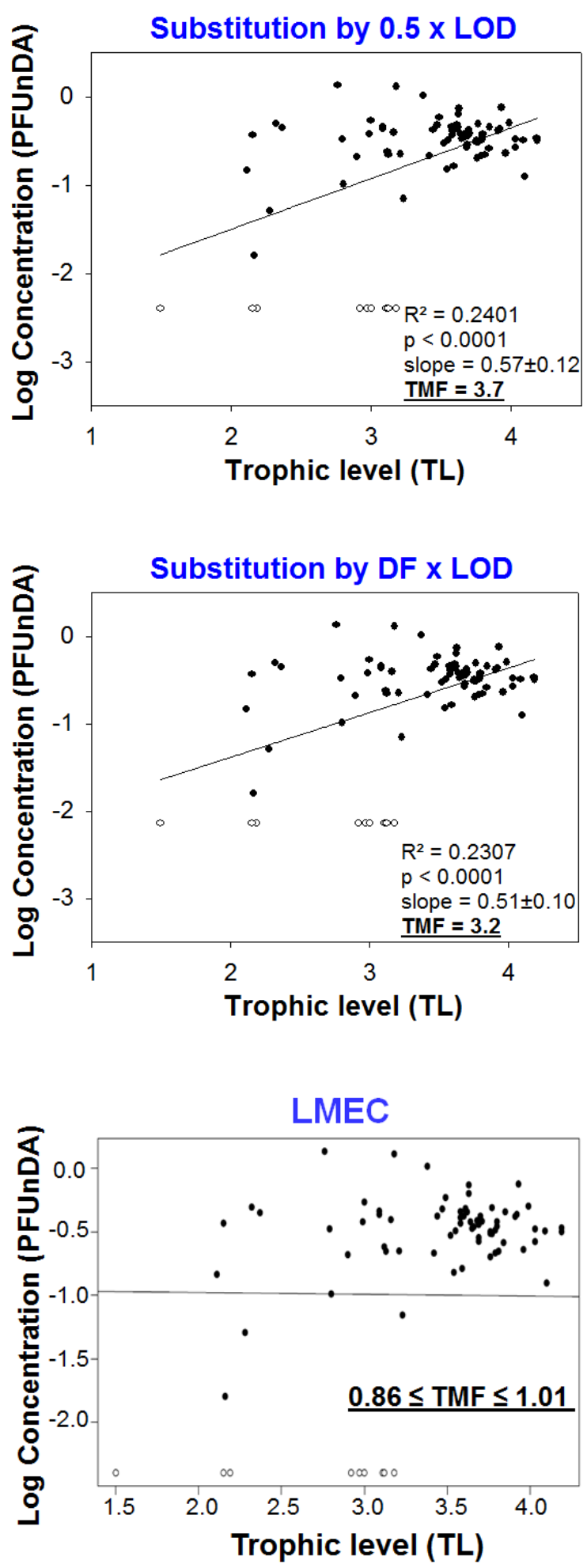

Fig.4. Illustration of Log (CPFUnDA) (concentrations expressed in $\mathrm{ng} \mathrm{g}^{-1}$ ww whole body) Vs trophic level (TL) regression lines and the resulting TMFs in the case of the intermediate demersal food web, using traditional substitution techniques (substitution of non-detects by either $0.5 \times$ LOD or DF $\times$ LOD) (DF: detection frequency) and an alternative approach based on linear mixed effect models with censored responses (LMEC). 
Table 1. Overall detection frequency (\%) and concentration range (min-max) (ng g-1 wet weight whole-body (ww w-b)) of PFASs in biota from the Gironde estuary food web $(N=147)$ and summary of trophic magnification factors (TMFs). TMFs were determined with a linear mixed effect model with censored responses (Imec function of the LMEC R-package) (TMF estimate, TMF $95 \%$ confidence interval, and Akaike information criterion AIC). TMFs significantly different from 1 are indicated in bold.

\begin{tabular}{|c|c|c|c|c|}
\hline & $\begin{array}{c}\text { Detection } \\
\text { Frequency } \\
(\%) \\
\end{array}$ & $\begin{array}{c}\text { Concentration } \\
\text { range (min-max) } \\
\left(\mathrm{ng} \mathrm{g}^{-1} \mathrm{ww} w-b\right)\end{array}$ & $\begin{array}{c}\operatorname{TMF}_{\text {BENTHIC }}(\mathbf{n}=\mathbf{6 7}) \\
\text { Estimate }[95 \%](\mathrm{AIC})\end{array}$ & $\begin{array}{l}\text { TMF }_{\text {DEMERSAL }}(\mathbf{n}=\mathbf{8 0}) \\
\text { Estimate }[95 \%](\text { AIC) }\end{array}$ \\
\hline PFHpA & 18 & $N D^{*}-1.7$ & $\mathrm{NC}^{* *}$ & NC \\
\hline PFOA & 63 & ND-8.2 & $6.0[5.0 ; 7.3](120)$ & $1.0[0.91 ; 1.1](101)$ \\
\hline PFNA & 91 & ND-12 & $3.1[2.7 ; 3.5](116)$ & $\mathbf{0 . 8 8}[0.81 ; 0.97](122)$ \\
\hline PFDA & 95 & ND-4.1 & $1.7[1.6 ; 1.9](100)$ & $0.96[0.91 ; 1.0](74)$ \\
\hline PFUnDA & 90 & ND-4.0 & $1.8[1.6 ; 2.0](139)$ & $0.93[0.86 ; 1.0](110)$ \\
\hline PFDoDA & 93 & ND-2.8 & $1.1[0.94 ; 1.2](150)$ & $1.3[1.1 ; 1.4](154)$ \\
\hline PFTrDA & 86 & ND-2.4 & $\mathbf{0 . 6 6}[0.49 ; 0.87](196)$ & $0.96[0.89 ; 1.0](120)$ \\
\hline PFTeDA & 59 & ND-0.35 & $0.33[0.20 ; 0.54](221)$ & $1.2[1.0 ; 1.5](246)$ \\
\hline PFHxS & 62 & ND-1.3 & $4.3[3.5 ; 5.1](116)$ & $1.5[1.2 ; 1.9](196)$ \\
\hline PFHpS & 31 & ND-1.1 & $N A^{* * *}$ & NA \\
\hline Br-PFOS & 95 & ND-6.6 & $3.9[3.3 ; 4.6](156)$ & $1.5[1.3 ; 1.6](124)$ \\
\hline L-PFOS & 100 & $0.085-22$ & $2.5[2.3 ; 2.6](81)$ & $0.94[0.92 ; 0.97](33)$ \\
\hline PFDS & 21 & ND-0.077 & NA & NA \\
\hline MeFOSAA & 50 & ND-0.58 & NA & $0.18[0.08 ; 0.42](287)$ \\
\hline EtFOSAA & 30 & ND-0.43 & NA & NA \\
\hline FOSA & 100 & $0.057-5.4$ & 2.3 [2.2;2.4] (237) & $1.2[1.20 ; 1.25](8)$ \\
\hline MeFOSA & 1 & ND-0.080 & $\mathrm{NC}$ & NC \\
\hline ¿PFASs & - & $0.66-45$ & - & - \\
\hline
\end{tabular}

${ }^{*} \mathrm{ND}$ : not detected (<LOD). ${ }^{* \star} \mathrm{NC}$ : not calculated (censoring percentage $\left.>80 \%\right) .{ }^{* \star} \mathrm{NA}$ : not available.

In the benthic food web, TMFs were $>1$ for nearly all the compounds considered. Another salient feature of the benthic food web was the particularly high TMFs of PFOA and PFNA (6.0 and 3.1, respectively). In fact, TMFs computed for benthic taxa followed an exponential decrease with increasing perfluoroalkyl chain length for $\mathrm{C}_{8}-\mathrm{C}_{14}$ PFCAs (SI Fig.S6). Previous studies reported different trends in pelagic marine Arctic food webs ${ }^{24,25}$ or in temperate lakes, ${ }^{69}$ which indicates that PFAS chemical structure might not be necessarily predictive of TMFs in aquatic ecosystems and further suggests that biomagnification is influenced by the ecosystem characteristics. ${ }^{19}$ TMFs were significantly $<1$ in the benthic food web for PFTrDA and PFTeDA, suggesting apparent biodilution (Table 1). Likewise, the linear isomer of PFOS (TMF $=2.5$ ) was less readily biomagnified than PFHxS or Br-PFOS (TMF = 3.9-4.3). 
In summary, higher levels of PFASs were generally found in benthic-dwelling biota, with differing bioaccumulation profiles compared to pelagic biota. In the benthic food web, trophic magnification was more pronounced for PFHxS, PFOA or PFNA than for their longer-chain analogs, while no particular trend emerged in the demersal food web. This study stresses once again that the validity of TMFs hinges on appropriate study design and data treatment. In future work studying the influence of environmental and ecological parameters on PFAS bioaccumulation and biomagnification potential, the authors reiterate the need for appropriate sampling design, well-vetted analytical methods, and suitable statistical procedures. To endorse conclusions based on laboratory- or field-derived measurements, contaminant concentrations should be standardized across the species studied (e.g., whole body burden). Particular care should also be given to seasonal variations in levels of contaminants and $\delta^{15} \mathrm{~N}$, analytical artifacts, and statistical processing of left-censored data. In that respect, substitution approaches of non-detects (e.g., $0.5 \times$ LOD) should be avoided. Environmental factors not considered in the present study (e.g. salinity gradient), biological variables (e.g. sex, physical condition), as well as potential exposure to additional co-occurring precursors, could also possibly influence the bioaccumulation and biomagnification potential of perfluoroalkyl acids at land/sea interfaces. ${ }^{27,49,70-72}$

\section{Associated content}

Supporting Information. Chemicals and solvents, collection of water and sediment samples, LCMS/MS operating details, R scripts for the determination of TMFs via cenken and Imec, analytical method validation, $Q A / Q C$, stable isotope signature of biota samples, determination of muscle to whole-body PFAS concentrations, values for the $\alpha$ and $(1-\alpha)$ coefficients, PFAS concentration ranges in surface water and sediment samples, PFAS mean abundance profiles for each biota species, PFAS concentration ranges in biota samples, bioaccumulation and biomagnification factors, trophic magnification factors via cenken. 


\section{Acknowledgments}

The authors are thankful to Virginie Bocquet, Emmanuel Geneste, and Patrick Pardon for their contribution to this study. Excellent assistance in field work (zooplankton and nekton harvesting) was provided by Mariange Cornet and Nathalie Tapie. This study has been carried out under the framework of the PFC-Gironde CNRS project (EC2CO-Ecodyn INSU) and with financial support from the French National Research Agency (ANR). This study was conducted in the frame of the 'Investments for the future' Program, within the Cluster of Excellence COTE (ANR-10-LABX-45). IdEx Bordeaux (ANR-10-IDEX-03-02) provided the PhD grant allocated to G. Munoz. The authors also acknowledge funding from ORQUE SUDOE (SOE3/P2/F591), as well as the Aquitaine Regional Council and the European Union (CPER A2E project). Europe is moving in Aquitaine with the European Regional Development Fund (FEDER). 


\section{References}

[1] Gobas, F. A. P. C.; de Wolf, W.; Burkhard, L. P.; Verbruggen, E.; Plotzke, K. Revisiting bioaccumulation criteria for POPs and PBT assessments. Integr. Environ. Assess. Manag. 2009, 5, 624-636.

[2] Muir, D. C. G; Howard, P. H. Are there other persistent organic pollutants? A challenge for environmental chemists. Environ. Sci. Technol. 2006, 40, 7157-7166.

[3] Moody, C. A.; Field, J.A. Determination of perfluorocarboxylates in groundwater impacted by fire-fighting activity. Environ. Sci. Technol. 1999, 33, 2800-2806.

[4] Giesy, J. P.; Kannan, K. Global distribution of perfluorooctane sulfonate in wildlife. Environ. Sci. Technol. 2001, 35, 1339-1342.

[5] Rankin, K.; Mabury, S. A.; Jenkins, T. M.; Washington, J. W. A North American and global survey of perfluoroalkyl substances in surface soils: Distribution patterns and mode of occurrence. Chemosphere, 2016, 161, 333-341.

[6] Yeung, L. W. Y.; Dassuncao, C.; Mabury, S. A.; Sunderland, E. M.; Zhang, X.; Lohmann, R. Vertical Profiles, Sources and Transport of PFASs in the Arctic Ocean. Environ. Sci. Technol. 2017, 51, 6735-6744.

[7] http://chm.pops.int/TheConvention/ThePOPs/ListingofPOPs/tabid/2509/Default.aspx.

[8] Martin, J. W.; Mabury, S. A.; Solomon, K.; Muir, D. C. G. Bioconcentration and tissue distribution of perfluorinated acids in rainbow trout (Oncorhynchus mykiss). Environ. Toxicol. Chem. 2003, 22, 196-204.

[9] Olivero-Verbel, J.; Tao, L.; Johnson-Restrepo, B.; Guette-Fernández, J.; Baldiris-Avila, R.; O'byrneHoyos, I.; Kannan, K. Perfluorooctanesulfonate and related fluorochemicals in biological samples from the north coast of Colombia. Environ. Pollut. 2006, 142, 367-372.

[10] Conder, J. M.; Hoke, R. A.; de Wolf, W.; Russell, M. H.; Buck, R. C. Are PFCAs bioaccumulative? A critical review and comparison with regulatory criteria and persistent lipophilic compounds. Environ. Sci. Technol. 2008, 42, 995-1003.

[11] Kwadijk, C. J. A. F.; Korytár, P.; Koelmans, A. A. Distribution of perfluorinated compounds in aquatic systems in The Netherlands. Environ. Sci. Technol. 2010, 44, 3746-3751.

[12] Labadie, P.; Chevreuil, M. Partitioning behaviour of perfluorinated alkyl contaminants between water, sediment and fish in the Orge River (nearby Paris, France). Environ. Pollut. 2011, 159, 391-397.

[13] Ahrens, L.; Norström, K.; Viktor, T.; Cousins, A. P.; Josefsson, S. Stockholm Arlanda Airport as a source of per- and polyfluoroalkyl substances to water, sediment and fish. Chemosphere 2015, 129, 33-38.

[14] Hong, S.; Khim, J. S.; Wang, T.; Naile, J.E.; Park, J.; Kwon, B. O.; Song, S. J.; Ryu, J.; Codling, G.; Jones, P. D.; Lu, Y.; Giesy, J. P. Bioaccumulation characteristics of perfluoroalkyl acids (PFAAs) in coastal organisms from the west coast of South Korea. Chemosphere 2015, 129, 157-163.

[15] REACh Annex XIII on Criteria for the identification of persistent, bioaccumulative and toxic substances, and very persistent and very bioaccumulative substances (<http://www.reachonline.eu/REACH/EN/REACH_EN/articleXIII.html>).

[16] Nakata, H.; Kannan, K.; Nasu, T.; Cho, H. S.; Sinclair, E.; Takemura, A. Perfluorinated contaminants in sediments and aquatic organisms collected from shallow water and tidal flat areas of the Ariake Sea, Japan: environmental fate of perfluorooctane sulfonate in aquatic ecosystems. Environ. Sci. Technol. 2006, 40, 4916-4921.

[17] Loi, E. I. H.; Yeung, L. W. Y.; Taniyasu, S.; Lam, P. K. S.; Kannan, K.; Yamashita, N. Trophic magnification of poly- and perfluorinated compounds in a subtropical food web. Environ. Sci. Technol. 2011, 45, 5506-5513.

[18] Bertin, D.; Ferrari, B. J. D.; Labadie, P.; Sapin, A.; Garric, J.; Budzinski, H.; Houde, M.; Babut, M. Bioaccumulation of perfluoroalkyl compounds in midge (Chironomus riparius) larvae exposed to sediment. Environ. Pollut. 2014, 189, 27-34. 
[19] Borgå, K.; Kidd, K. A.; Muir, D. C. G.; Olof, B.; Conder, J. M.; Gobas, F. A. P. C.; Kucklick, J.; Malm, O.; Powell, D. E. Trophic magnification factors: considerations of ecology, ecosystems, and study design. Integr. Environ. Assess. Manag. 2011, 8, 64-84.

[20] Jardine, T. D.; Kidd, K. A.; Fisk, A. T. Applications, considerations, and sources of uncertainty when using stable isotope analysis in ecotoxicology. Environ. Sci. Technol. 2006, 40, 7501-7511.

[21] Martin, J. W.; Whittle, D. M.; Muir, D. C. G.; Mabury, S. A. Perfluoroalkyl contaminants in a food web from Lake Ontario. Environ. Sci. Technol. 2004, 38, 5379-5385.

[22] Tomy, G. T.; Budakowski, W.; Halldorson, T.; Helm, P. A.; Stern, G. A.; Friesen, K.; Pepper, K.; Tittlemier, S. A.; Fisk A. T. Fluorinated organic compounds in an eastern arctic marine food web. Environ. Sci. Technol. 2004, 38, 6475-6481.

[23] Houde, M.; Bujas, T.D.; Small, J.; Fair, P.; Bossart, G. D.; Solomon, K.; Muir, D. C. G. Biomagnification of perfluoroalkyl compounds in the bottlenose dolphin (Tursiops truncatus) food web. Environ. Sci. Technol. 2006, 40, 4138-4144.

[24] Kelly, B. C.; Ikonomou, M. G.; Blair, J. D.; Surridge, B.; Hoover, D.; Grace, R.; Gobas, F. A. P. C. Perfluoroalkyl Contaminants in an Arctic Marine Food Web: Trophic Magnification and Wildlife Exposure. Environ. Sci. Technol. 2009, 43, 4037-4043.

[25] Tomy, G. T.; Pleskach, K.; Ferguson, S. H.; Hare, J.; Stern, G.; Macinnis, G.; Marvin, C. H.; Loseto, L. Trophodynamics of some PFCs and BFRs in a western Canadian arctic marine food web. Environ. Sci. Technol. 2009, 43, 4076-4081.

[26] Xu, J.; Guo, C. S.; Zhang, Y.; Meng, W. Bioaccumulation and trophic transfer of perfluorinated compounds in a eutrophic freshwater food web. Environ. Pollut. 2014, 184, 254-261.

[27] Houde, M.; De Silva, A. O.; Muir, D. C. G.; Letcher, R. J. Monitoring of perfluorinated compounds in aquatic biota: an updated review. Environ. Sci. Technol. 2011, 45, 7962-7973.

[28] Wang, J.; Zhang, Y.; Zhang, F.; Yeung, L. W.; Taniyasu, S.; Yamazaki, E.; Wang, R.; Lam, P. K. S.; Yamashita, N.; Dai, J. Age- and gender-related accumulation of perfluoroalkyl substances in captive Chinese alligators (Alligator sinensis). Environ. Pollut. 2013, 179, 61-67.

[29] Franklin, J. How reliable are field-derived biomagnification factors and trophic magnification factors as indicators of bioaccumulation potential? Conclusions from a case study on per-and polyfluoroalkyl substances. Integrated Environmental Assessment and Management 2016, 12, 6-20.

[30] Vaida, F.; Liu, L. Fast implementation for normal mixed effects models with censored response. J. Comput. Graph. Stat. 2009, 18, 797-817.

[31] Lescord, G. L.; Kidd, K. A.; De Silva, A. O.; Williamson, M.; Spencer, C.; Wang, X.; Muir, D. C. G. Perfluorinated and polyfluorinated compounds in lake food webs from the Canadian high arctic. Environ. Sci. Technol. 2015, 49, 2694-2702.

[32] de Vos, M. G.; Huijbregts, M. A. J.; van den Heuvel-Greve, M. J.; Vethaak, A. D.; Van de Vijver, K. I.; Leonards, P. E. G.; van Leeuwen, S. P. J.; de Voogt, P.; Hendriks, A. J.; Accumulation of perfluorooctane sulfonate (PFOS) in the food chain of the Western Scheldt estuary: Comparing field measurements with kinetic modeling. Chemosphere 2008, 70, 1766-1773.

[33] Pasquaud, S.; Pillet, M.; David, V.; Sautour, B.; Elie, P. Determination of fish trophic levels in an estuarine system. Est. Coast. Shelf Sci. 2010, 86, 237-246.

[34] Allen, G. P., Salomon, J. C.; Bassoullet, P.; Du Penhoat, Y.; De Grandpré, C. Effects of tides on mixing and suspended sediment transport in macrotidal estuaries. Sedim. Geol. 1980, 26, 69-90.

[35] Sottolichio, A.; Castaing, P. A synthesis on seasonal dynamics of highly-concentrated structures in the Gironde estuary. C.R. Acad. Sci. 1999, Sér. II Fasc.A-Sci. Terre Planètes 329, 795-800.

[36] Lobry, J.; David, V.; Pasquaud, S.; Lepage, M.; Sautour, B.; Rochard, E. Diversity and stability of an estuarine trophic network. Mar. Ecol. Prog. Ser. 2008, 35, 13-25.

[37] Lobry, J.; Mourand, L.; Rochard, E.; Elie, P. Structure of the Gironde estuarine fish assemblages: a comparison of European estuaries perspective. Aquatic Living Res. 2003, 16, 47-58. 
[38] David, V.; Sautour, B.; Chardy, P.; Leconte, M. Long-term changes of the zooplankton variability in a turbid environment: the Gironde estuary (France). Estuar. Coast. Shelf Sci. 2005, 64, 171-184.

[39] Selleslagh, J.; Lobry, J.; N'Zigou, A. R.; Bachelet, G.; Blanchet, H.; Chaalali, A.; Sautour, B.; Boët, P. Seasonal succession of estuarine fish, shrimps, macrozoobenthos and plankton: Physico-chemical and trophic influence. The Gironde estuary as a case study. Est. Coast. Shelf Sci. 2012, 112, 243-254.

[40] Budzinski, H.; Jones, I.; Bellocq, J.; Piérard, C.; Garrigues, P. Evaluation of sediment contamination by polycyclic aromatic hydrocarbons in the Gironde estuary. Mar. Chem. 1997, 58, 85-97.

[41] Baudrimont, M.; Schäfer, J.; Marie, V.; Maury-Brachet, R.; Bossy, C.; Boudou, A.; Blanc, G. Geochemical survey and metal bioaccumulation of three bivalve species (Crassostrea gigas, Cerastoderma edule and Ruditapes philippinarum) in the Nord Médoc salt marshes (Gironde estuary, France). Sci. Total Environ. 2005, 337, 265-280.

[42] Tapie, N.; Le Menach, K.; Pasquaud, S.; Elie, P.; Devier, M.H.; Budzinski, H. PBDE and PCB contamination of eels from the Gironde estuary: From glass eels to silver eels. Chemosphere 2011, 83, 175-185.

[43] Chaalali A.; Chevillot X.; Beaugrand G.; David V.; Luczak C.; Boët P.; Sottolichio A.; Sautour B. Changes in the zooplankton community distribution in the Gironde estuary: A marinisation consequence? Est. Coast. Shelf Sci. 2013, 134, 150-161.

[44] Bodin, N.; Tapie, N.; Le Ménach, K.; Chassot, E.; Elie, P.; Rochard, E.; Budzinski, H. PCB contamination in fish community from the Gironde Estuary (France): Blast from the past. Chemosphere 2014, 98, 66-72.

[45] Munoz, G.; Giraudel, J. L.; Botta, F.; Lestremau, F.; Dévier, M.H.; Budzinski, H.; Labadie, P. Spatial distribution and partitioning behavior of selected poly- and perfluoroalkyl substances in freshwater ecosystems: a French nationwide survey. Sci. Total Environ. 2015, 517, 48-56.

[46] Munoz, G.; Fechner, L. C.; Geneste, E.; Pardon, P.; Budzinski, H.; Labadie, P. Spatio-temporal dynamics of per and polyfluoroalkyl substances (PFASs) and transfer to periphytic biofilm in an urban river: case-study on the River Seine. Environ. Sci. Pollut. Res. 2016, 1-9.

[47] Munoz, G.; Vo Duy, S.; Budzinski, H.; Labadie, P.; Liu, J.; Sauvé, S. Quantitative analysis of poly- and perfluoroalkyl compounds in water matrices using high resolution mass spectrometry: Optimization for a laser diode thermal desorption method. Anal. Chim. Acta 2015, 881, 98-106.

[48] Reiner, J. L.; O’Connell, S. G.; Butt, C. M.; Mabury, S. A.; Small, J. M.; De Silva, A. O.; Muir, D. C. G.; Delinsky, A. D.; Strynar, M. J.; Lindstrom, A. B.; Reagen, W. K.; Malinsky, M.; Shäfer, S.; Kwadijk, C. J. A. F.; Schantz, M. M.; Keller, J. M. Determination of perfluoroalkyl acid concentrations in biological standard reference materials. Anal. Bioanal. Chem. 2012, 404, 2683-2692.

[49] Munoz, G.; Desrosiers, M.; Duy, S. V.; Labadie, P.; Budzinski, H.; Liu, J.; Sauvé, S. Environmental occurrence of perfluoroalkyl acids and novel fluorotelomer surfactants in the freshwater fish Catostomus commersonii and sediments following firefighting foam deployment at the Lac-Mégantic railway accident. Environ. Sci. Technol. 2017, 51, 1231-1240.

[50] Bodin, N.; Budzinski, H.; Le Menach, K.; Tapie, N. ASE extraction method for simultaneous carbon and nitrogen stable isotope analysis in soft tissues of aquatic organisms. Anal. Chim. Acta 2009, 643, 54-60.

[51] Post, D. M. Using stable isotopes to estimate trophic position: models, methods, and assumptions. Ecology 2002, 83, 703-718.

[52] Pasquaud, S.; Elie, P.; Jeantet, C.; Billy, I.; Martinez, P.; Girardin, M. A preliminary investigation of the fish food web in the Gironde estuary, France, using dietary and stable isotope analyses. Est. Coastal Shelf Sci. 2008, 78, 267-279.

[53] Fair, P. A.; Houde, M.; Hulsey, T. C.; Bossart, G. D.; Adams, J.; Balthis, L.; Muir, D. C. G. Assessment of perfluorinated compounds (PFCs) in plasma of bottlenose dolphins from two southeast US estuarine areas: relationship with age, sex and geographic locations. Mar. Pollut. Bull. 2012, 64, 66-74.

[54] So, M. K.; Taniyasu, S.; Lam, P. K. S.; Zheng, G. J.; Giesy, J. P.; Yamashita, N. Alkaline digestion and solid phase extraction method for perfluorinated compounds in mussels and oysters from south China and Japan. Arch. Environ. Contam. Toxicol. 2006, 50, 240-248. 
[55] Stevenson, C. N.; MacManus-Spencer, L. A.; Luckenbach, T.; Luthy, R. G.; Epel, D. New perspective on perfluorochemical ecotoxicology: Inhibition and induction of an efflux transporter in the marine mussel, Mytilus californianus. Environ. Sci. Technol. 2006, 40, 5580-5585.

[56] Haukas, M.; Berger, U.; Hop, H.; Gulliksen, B.; Gabrielsen, G. W. Bioaccumulation of per- and polyfluorinated alkyl substances (PFAS) in selected species from the Barents Sea food web. Environ. Pollut. 2007, 148, 360-371.

[57] Munschy, C.; Marchand, P.; Venisseau, A.; Veyrand, B.; Zendong, Z. Levels and Trends of the Emerging Contaminants HBCDs (hexabromocyclododecanes) and PFCs (perfluorinated Compounds) in Marine Shellfish along French Coasts. Chemosphere 2013, 91, 233-240.

[58] Benskin, J. P.; Ikonomou, M. G.; Gobas, F. A.; Begley, T. H.; Woudneh, M. B.; Cosgrove, J. R. Biodegradation of $\mathrm{N}$-ethyl perfluorooctane sulfonamido ethanol (EtFOSE) and EtFOSE-based phosphate diester (SAmPAP diester) in marine sediments. Environ. Sci. Technol. 2013, 47, 1381-1389.

[59] Mejia-Avendaño, S.; Vo Duy, S.; Sauvé, S.; Liu, J. Generation of perfluoroaklyl acids from aerobic biotransformation of quaternary ammonium polyfluoroalkyl surfactants. Environ. Sci. Technol. 2016, 50, 9923-9932.

[60] Martin, J. W.; Asher, B. J.; Beesoon, S.; Benskin, J. P.; Ross, M. S. PFOS or PreFOS? Are perfluorooctane sulfonate precursors (PreFOS) important determinants of human and environmental perfluorooctane sulfonate (PFOS) exposure? Journal of Environmental Monitoring 2010, 12, 1979-2004.

[61] Galatius, A.; Bossi, R.; Sonne, C.; Rigét, F. F.; Kinze, C. C.; Lockyer, C.; Teilmann, J.; Dietz, R. PFAS profiles in three North Sea top predators: metabolic differences among species? Environmental Science and Pollution Research 2013, 20, 8013-8020.

[62] Gebbink, W. A.; Bignert, A.; Berger, U. Perfluoroalkyl Acids (PFAAs) and Selected Precursors in the Baltic Sea Environment: Do Precursors Play a Role in Food Web Accumulation of PFAAs? Environ. Sci. Technol. 2016, 50, 6354-6362.

[63] Dassuncao, C.; Hu, X. C.; Zhang, X.; Bossi, R.; Dam, M.; Mikkelsen, B.; Sunderland, E. M. Temporal Shifts in Poly-and Perfluoroalkyl Substances (PFASs) in North Atlantic Pilot Whales Indicate Large Contribution of Atmospheric Precursors. Environ. Sci. Technol. 2017, 51, 4512-4521.

[64] Higgins, C. P.; McLeod, P. B.; MacManus-Spencer, L. A.; Luthy, R. G. Bioaccumulation of perfluorochemicals in sediments by the aquatic oligochaete Lumbriculus variegatus. Environ. Sci. Technol. 2007, 41, 4600-4606.

[65] Vedel, A.; Riisgård, H. U. Filter-feeding in the polychaete Nereis diversicolor: growth and bioenergetics. Mar. Ecol. Prog. Ser. 1993, 100, 145-152.

[66] Armitage, J. M.; Arnot, J. A.; Wania, F.; Mackay, D. Development and evaluation of a mechanistic bioconcentration model for ionogenic organic chemicals in fish. Environmental Toxicology and Chemistry 2013, 32, 115-128.

[67] Spitz, J.; Mourocq, E.; Schoen, V.; Ridoux, V. Proximate composition and energy content of forage species from the Bay of Biscay: high-or low-quality food? ICES Journal of Marine Science: Journal du Conseil 2010, 67, 909-915.

[68] Helsel, D. R. Statistics for Censored Environmental Data Using Minitab and R, 2012, 2nd ed. Wiley.

[69] Fang, S.; Chen, X.; Zhao, S.; Zhang, Y.; Jiang, W.; Yang, L.; Zhu, L. Trophic Magnification and Isomer Fractionation of Perfluoroalkyl Substances in the Food Web of Taihu Lake, China. Environ. Sci. Technol. 2014, 48, 2173-2182.

[70] Van Ael, E.; Covaci, A.; Das, K.; Lepoint, G.; Blust, R.; Bervoets, L. Factors influencing the bioaccumulation of persistent organic pollutants in food webs of the Scheldt estuary. Environ. Sci. Technol. 2013, 47, 11221-11231.

[71] Munoz, G.; Vo Duy, S.; Labadie, P.; Botta, F.; Budzinski, H.; Lestremau, F.; Liu, J.; Sauvé, S. Analysis of zwitterionic, cationic, neutral and anionic polyfluoroalkyl surfactants in sediments by liquid chromatography polarity-switching electrospray ionization coupled to Orbitrap mass spectrometry. Talanta 2016, 152, 447-456. 
[72] Barzen-Hanson, K. A.; Roberts, S. C.; Choyke, S.; Oetjen, K.; McAlees, A.; Riddell, N.; McCrindle, R.; Lee Ferguson, P.; Higgins, C. P.; Field, J.A. Discovery of 40 Classes of Per- and Polyfluoroalkyl Substances in Historical Aqueous Film-Forming Foams (AFFFs) and AFFF-Impacted Groundwater. Environ. Sci. Technol. 2017, 51, 2047-2057. 